\title{
From Editor's Desk
}

\section{Acknowledgement}

Launching of new peer reviewed Medical journal was challenging tasks, with the publication of $2^{\text {nd }}$ issue of volume 2 of Journal of Aziz Fatimah Medical and Dental College (JAFMDC); our journal has completed 2 years of production. During this tenure we have published 4 peer reviewed medical journals ( 2 volumes with 2 issues in each) with great success. It is an honor to get numerous letter of appreciation from all over the Pakistan. We achieved our first milestone by hardships and joint efforts of editorial team and now we are eligible to apply for its recognition by Higher Education Commission (HEC).

We initiated this journal with the goal to produce a high-quality, plagiarism free peer reviewed journal in field of medical sciences that adds information to the world's medical literature from Pakistan. This success is impossible without the vision of Mr. Muhamad Idrees (Managing Trustee) who always encourages us to go beyond our comfort zone to achieve the set milestone. I would like to pay my especial gratitude to Mr. Ijaz Hussain (Executive director) to support in all the logistic required for this journal. On achieving the first Milestone, as an editor, I wish to extend my thanks to JAFMDC's Editorial board members especially to Dr. Farah Amir Ali, Dr. Benash Altaf and Dr. Mirza Aroosa Beg for helping me to achieve this task. On behalf of my team, I am grateful to our worthy Principal NoorAkbar Sial and senior manager administrator Mr. Aftab Ali khan, who have always been the pillar of unconditional support in all matters.

As JAFMDC achieved its first Milestone, we would like to acknowledge all authors who submitted their valuable research work to JAFMDC in spite of knowing that this is a new medical journal and still in phase of struggling for recognition with HEC. Of course, the contributions of reviewers towards JAFMDC are also appreciating that help us in provision of articles up to the mark of scientific excellence for readers.

We are also grateful to the legends of medical journalism Mr. Shaukat Ali Jawaid, Dr Fatema Jawad, Dr. Akhter Sherin, Dr. Jamshed Akhter, whose guidance during certificate in medical editing course (CME) at University of Health Sciences Lahore (UHS) helped us to overcome our shortcomings. Once again especial regards to Mr.Shaukat Ali Jawaid for his valuable suggestions to improve the quality of JAFMDC. We are thankful to Dr. Masood Jawaid for his guidance concerning Open Journal System (OJS) for transparent processing of articles. Now we are waiting for the advanced CME course to get more guidance concerning indexing of the journals.

We hope that our journal will continue to be an important conduit for scientific information with international standards.

\section{EDITOR JAFMDC}

Dr. Shireen Jawed

Email: drshireenjawed@gmail.com 